\title{
Integración de los graduados universitarios en el mercado profesional. Formación en competencias horizontales.
}

\section{Integration of college graduates in the professional market. Horizontal skills training}

\author{
Rocío Gómez-Juncal, Dolores Dopico, Silvia García, Cristina Varela \\ Universidade de Vigo
}

\begin{abstract}
Resumen
As habilidades sociais de comunicación, por ser capacidades cognitivas que se veñen demandando cada vez con máis forza na sociedade da información actual, onde os cambios son constantes e requiren dunha adaptación aos mismos de forma fluida e versátil, son capacidades que é necesario coñecer para afondar no seu desenvolvemento, xa que as empresas cada vez as valoran máis, sendo a súa importancia tal que poden marcar a diferencia á hora de conseguir un emprego. Ante currículums similares, as habilidades sociais soen decantar a balanza hacia aqueles candidatos que destacan polas "destrezas" como a seguridade nun mesmo ou o control emocional. Por todo 0 anteriormente exposto, consideramos que a intervención na mellora do coñecemento das potencialidades dos recén titulados, os situará en mellor lugar na consecución dun posto de emprego adaptado ás súas necesidades, por eso axudarlles a conseguir unha presentación óptima do seu perfil profesional, conseguir que preparen o seu dossier de traballos realizados durante a súa formación universitaria, conseguindo que os presenten dun xeito que transmita seguridade ó empregador, fará que os recén titulados estean nunha posición de ventaxa frente a outros iguais que non recibiran este tipo de formación. Neste traballo de investigación preténdese comparar entre dous grupos de titulados universitarios, que se diferencian na formación en habilidades sociais profesionais, as diferencias na incorporación laboral en diferentes áreas: tempo de espera para a incorporación, calidade e adaptación á mesma, entendendo que a intervención educativa transversal terá impacto no éxito na incorporación profesional, e a autopercepción exitosa neste aspecto.
\end{abstract}

Palabras chave: Formación, competencias horizontais, competencias profesionais, emprego

\section{Abstract}

Social skills of communication, as cognitive abilities that are demanding ever more strongly in the information society today, where change is constant and require an adaptation to themselves fluently and versatile capabilities that are necessary to know deeply in its development, as companies increasingly value the most, and its importance so that may make a difference in getting a job. Before curriculums similar social skills tend to decant the balance towards candidates who stand for "skills" as security in the same or emotional control. For all the above, we consider that the intervention in improving the knowledge of the potential of newly graduates, placed in the best place in achieving a post employment tailored to their needs, so help them achieve optimal presentation of your professional profile, get prepare your dossier of work performed during their university education, managing the present in a way that conveys security or employer will make the newly graduates are in a position of advantage against others like it had not received such training. In this research work aims to compare two groups of graduates, which differ in social skills training professionals, the differences in labor incorporation in different areas: waiting time for incorporation, quality and adaptation to it, understanding that educational intervention will impact the success in professional incorporating, successful and self-awareness in this regard.

Keywords: Training, horizontal skills, professional skills, job.

\section{Introducción}

Un dos obxectivos da implantación do Espazo Europeo de Educación Superior (EEES) é a promoción das condicións e situacións de aprendizaxe nas que se deseñen experiencias próximas ás necesidades profesionais, incorporando a formación continuada como fórmula de aprendizaxe, para axudar ós estudantes a conseguir os seus propósitos laborais e vitais.

Este proxecto de innovación educativa está baseado na experiencia previa obtida a través de diferentes aproximacións ó estudio das necesidades reais que tanto os graduados universitarios, como o mercado laboral, recoñecen como fundamentais para un desenvolvemento profesional satisfactorio persoalmente e útil para as necesidades que a sociedade demanda dos titulados universitarios.

Neste sentido, en diversas publicacións este equipo de investigación xa encontrou signos evidentes dos cambios que estamos vivindo no espazo de educación superior. En distintos estudios (Gómez-Juncal, et col., 2008; 2010; 2011) encontramos que ademáis da formación cualificada propia de cada disciplina, non se debe esquecer a adquisición de ferramentas de carácter social, de promoción da versatilidade, e por suposto a necesidade de desenvolver o pensamento social e creativo.

Nun estudo realizado por este equipo de investigación e financiado pola Cátedra Filgueira Valverde na convocatoria do 2009, outorgada por esta mesma Universidade, realizamos unha investigación na que compilamos información directa de empresas, asociacións e egresados universitarios (do ámbito do deseño), colectivos que forman parte dunha realidade laboral moi concreta. Neste caso os tres grupos que formaron parte da mostra coincidiron en identificar unha carencia na educación recibida centrada na necesidade de formación no desenvolvemento de competencias básicas de comunicación, e traballo en grupo, de resolución

Proxecto financiado ao abeiro do Programa de soporte para o desenvolvemento e implantación de acción de innovación educativa da Universidade de Vigo. Correspondendia: Rocío Gómez-Juncal,rogjuncal@uvigo.es

Selección y peer-review bajo responsabilidad del Grupo de Investigación G000422-GIPDAE, Universidade da Coruña, España. 
eficaz de problemas e traballo baixo condicións de estrés ou tensión; competencias que se deben desenvolver no percorrido que o estudante fai ó longo da súa formación superior, pero que non están suficientemente cubertas nas materias que forman parte dos seus plans de estudos.

\section{Antecedentes}

Coa sinatura da Declaración de Bolonia, ponse de manifiesto a relación entre a universidade e a sociedade no desenvolvemento das habilidades que permiten ao alumnado enfrentarse de xeito eficaz ás necesidades laborais reais e de construcción de coñecemento de forma autónoma.

Segundo estas bases os estudiantes universitarios deben lograr desenvolver, no seu proceso formativo, unha serie de competencias básicas non contempladas formalmente no currículum universitario ata este momento, polo que se fai necesaria a adaptación do sistema universitario para que o alumnado logre a consecución das mesmas.

Deste xeito un dos obxectivos prioritarios do Plan Bolonia é mellorar a "utilidade" da formación universitaria entendida en termos de empregabilidade dos seus graduados universitarios, facilitando a adecuación dos seus coñecementos ás demandas reais dos postos de traballo, respondendo á definición, formación e avaliación dos resultados dos ensinos como "relevantes profesionalmente" ou "relevantes para a sociedade".

Sen embargo, a realidade é outra, moitos estudios (Bennet, Foreman-Peck y Higgins, 1996; Hernández, 2005; Sayer y Studd, 2006), indican que os ensinos tradicionais en educación superior asumen que os grupos de estudiantes son homoxéneos en termos de idade, logros académicos e orientación, de ahí que os estilos de ensino-aprendizaxe tamén o sexan. Ademáis, a pesar da implantación progresiva dos novos plans de estudios adaptados ó Plan Bolonia, a realidade é que habitualmente as competencias transversais seguen sen figurar nas formacións e avaliacións das materias propias dos currículums dos graos universitarios.

Hoxe o rango de habilidades necesarias para responder á demanda empresarial é maior, as características dos estudiantes son máis diversificadas, e os métodos educativos tradicionais con clases maxistrais seguidas de tutorías xa non son axeitadas. É necesario contemplar na formación, ademáis dos coñecementos técnicos específicos de cada titulación, unha profundización nas habilidades comúns a tódolos ámbitos profesionais, un desenvolvemento das áreas transversais dos coñecementos, un maior control de habilidades sociais básicas (Biggs, 2003; McCormick, 2002).

As habilidades sociais de comunicación, por ser capacidades cognitivas que se veñen demandando cada vez con máis forza na sociedade da información actual, onde os cambios son constantes e requiren dunha adaptación aos mismos de forma fluida e versátil, son capacidades que é necesario coñecer para afondar no seu desenvolvemento, xa que as empresas cada vez as valoran máis, sendo a súa importancia tal que poden marcar a diferencia á hora de conseguir un emprego. Ante currículums similares, as habilidades sociais soen decantar a balanza hacia aqueles candidatos que destacan polas “destrezas" como a seguridade nun mesmo ou o control emocional (Gómez-Juncal et col. 2011).Por todo o anteriormente exposto, consideramos que a intervención na mellora do coñecemento das potencialidades dos recén titulados, os situará en mellor lugar na consecución dun posto de emprego adaptado ás súas necesidades, por eso axudarlles a conseguir unha presentación óptima do seu perfil profesional, conseguir que preparen o seu dossier de traballos realizados durante a súa formación universitaria, conseguindo que os presenten dun xeito que transmita seguridade ó empregador, fará que os recén titulados estean nunha posición de ventaxa frente a outros iguais que non recibiran este tipo de formación.

\section{Obxectivos}

Con esta acción de innovación educativa preténdense conseguir os seguintes obxectivos xerais:

- Mellorar a calidade da formación dos graduados universitarios.

- Contribuír á xeración de coñecementos e á innovación en metodoloxías de ensino-aprendizaxe mediante a investigación.

- Formar e perfeccionar profesionais universitarios que poden aportar un valor engadido no sector empresarial no que se incorporen.

Os obxectivos específicos deste proxecto son:

- Formar a futuros titulados universitarios en habilidades sociais básicas de elaboración e presentación do seu currículum vitae e porfolio de traballo, para a súa exposición eficaz.

- Promover a empregabilidade de titulados universitarios adaptando a súa formación real ás necesidades empresariais actuais.

- Obter probas experimentais dunha intervención específica en formación en habilidades sociais.

- Conseguir a medio e longo plazo unha maior taxa de contratación dos egresados universitarios.

- Cubrir a necesidade percibida no medio profesional do perfecciomento en habilidades sociais dos egresados universitarios.

\section{Metodoloxía de traballo}

$\mathrm{O}$ estudo pretende analizar o impacto real que a formación específica en habilidades profesionais ten na inserción laboral da mostra.

Para conseguir este obxectivo realouse unha selección mostral nas seguintes titulacións:

- Mestrado en arte contemporánea. Creación en investigación, na facultade de Belas Artes do campus de Pontevedra da Universidade de Vigo.

- Mestrado para o profesorado de educación secundaria, na facultade de Belas Artes do campus de Pontevedra da Universidade de Vigo.

- Mestrado en dirección de arte en publicidade, na facultade de Ciencias Sociais do campus de Pontevedra da Universidade de Vigo.

Realizamos unha convocatoria na que estos estudantes voluntariamente estivesen dispostos a participar nun módulo de formación específica para potenciar as súas 
posibilidades de inserción laboral, comunicándolles que este módulo formativo era totalmente gratuito e intensivo, e cuias prazas serían asignadas por orde de preinscripción, xerándose unha lista de agarda que sería utilizada en caso de baixa antes do inicio do módulo. Este primeiro chamamento aproveitouse para realizar unha primeira enquisa na que se recababan datos, ademáis do interés por participar no estudo, que nos desen unha visión xeral das expectativas profesionais, formativas e laborais, dos participantes (Anexo 1).

Ó grupo experimental foron asignados ó azar a metade dos voluntarios, o grupo control estivo composto pola outra metade.

Unha vez feita unha exhaustiva revisión bibliográfica, que analiza accións de intervención para resolver as necesidades formativas dos titulados universitarios, especialmente os estudos que tratan de medir o impacto da intervención educativa transversal no éxito profesional da mostra analizada (Alarcón, 2005; Caballo, 2005; Espada, 2007; Salanova, Grau, y Martínez, 2005), deseñouse un módulo de formación específico para a mostra experimental (en tres sesións de dúas horas e media cada unha) . Este módulo incluía formación referente ós seguintes puntos:

- Definición e importancia do concepto de competencias laborais xerais e específicas.

_ Elaboración e presentación do currículum vitae (deseño do contido, e coherencia co deseño estético)

_ Entrenamento para a preparación de entrevistas laborais.

- Complementos á entrevista laboral (cartas de presentación, cartas de motivación, e cartas de agradecemento)

_ Demandas laborais e estratexias de afrontamento (concepto de autoeficacia profesional).

_ Búsqueda de recursos profesionais (Axudas institucionais, plataformas de bolsas e financiación de proxectos, etc.)

O módulo de aprendizaxe do grupo control contou con contidos de aprendizaxe máis neutros (contidos teóricos sobre a preparación para o mundo laboral:preparación do curriculum vitae e preparación da entrevista laboral, nunha sesión de dúas horas e media).

Dez meses despóis do módulo de formación en ambos grupos mediuse a través dunha enquisa (Anexo 2) a percepción subxectiva da adaptación dos coñecementos adquiridos durante a súa formación á realidade laboral. Informábaselles de que serían enquisados unha terceira vez, 14 meses despóis da finalización dos seus estudios (Anexo 3), e que por cada enquisa se lles compensaría económicamente (de forma simbólica), sempre que se comprometesen a realizar a medición e a manter informado ó equipo de investigación das modificacións, se as houbese, dos seus datos de contacto persoais (Anexo 4). O pago pola realización das enquisas, tanto no grupo control como no grupo experimental ten dous obxectivos, por unha parte xerar a motivación suficiente nos participantes para que adiquen uns minutos para contestar ás preguntas que se lles realice, e por outra banda asegurarnos do compromiso que adquirirán para informar ó equipo de investigación das variacións dos seus datos persoais de contacto, se os houbese.

Por último, unha vez recopilada a información a través das enquisas, realizouse unha análise cualitativa e cuantitativa có fin de elaborar un informe exhaustivo das aptitudes e habilidades que cada grupo subliñou como necesarias para incorporarse ó mundo laboral e conservar, de ser o caso, o seu posto de traballo.

\section{Resultados}

A mostra inicial estivo constiruída por estudantes do Mestrado en arte contemporánea. Creación en investigación, na facultade de Belas Artes do campus de Pontevedra da Universidade de Vigo (19 alumno/as dos que aceptaron participar 9), Mestrado para o profesorado de educación secundaria, na facultade de Belas Artes do campus de Pontevedra da Universidade de Vigo (17 alumno/as dos que aceptaron participar 13), e Mestrado en dirección de arte en publicidade, na facultade de Ciencias Sociais do campus de Pontevedra da Universidade de Vigo (34 alumno/as dos que aceptaron participar 26). Un total de 48 participantes que foron asignados ao azar aos dous grupos (experimental e control), pero que foron reducíndose ao longo do proxecto, resultando nunha mortandade experimental do $62 \%$, e deixando unha mostra final de 18 participantes (ver Táboa 1).

Táboa 1

Mortandade experimental

\begin{tabular}{lcccc}
\hline & $\begin{array}{r}\text { Mostra } \\
\text { Potencial }\end{array}$ & $\begin{array}{r}\text { Mostra } \\
1^{\underline{a}} \text { enquisa }\end{array}$ & $\begin{array}{r}\text { Mostra } \\
2^{\underline{a}} \text { enquisa }\end{array}$ & $\begin{array}{r}\text { Mostra } \\
3^{\mathrm{a}} \text { enquisa }\end{array}$ \\
\hline G.E & 35 & 24 & 11 & 9 \\
G.C & 35 & 24 & 10 & 9 \\
TOTAL & 70 & 48 & 21 & 18
\end{tabular}

Unha vez analizada a mostra exporemos os resultados máis representativos das diferentes enquisas.

No caso da primeira enquisa, aquela na que participaron voluntariamente os estudantes dos distintos mestrados participantes, antes de participar no período de formación podemos destacar os seguintes resultados:

No referente á situación profesional dos participantes (antes de ser asignados a grupos control ou experimental):

Ante a pregunta "Buscou traballo relacionado coa súa formación?”, un 12,5\% non o fixo, un 31,3 \% buscouno e atopouno, máis un $56,3 \%$ buscouno pero non o atopou. $\mathrm{O}$ tempo medio de busca de emprego foi de 0 a 6 meses para un 59,1\%, de 6 meses a un ano para o 22,7\%, e máis de un ano para o $18,2 \%$.

No momento de medición estaba a traballar un $27,1 \%$, frente a un 72,9\% que non o estaba, e un 62,5\% declaraba 
ter traballado en postos relacionados directamente coa súa formación.

En canto á demanda de implicación da universidade na formación contínua de egresados, parece que os participantes consideran que as prácticas preprofesionais son imprescindibles para formación (90\% dos participantes valoran esta cuestión como prioirtaria); e valoran alonxados os contidos curriculares e a realidade laboral (90\% dos participantes)

Os participantes na enquisa valoran como cualidades máis importantes para a obtención dun emprego, nunha escala tipo Likert do 1 ao 4 (Táboa 2):

Táboa 2.

Valoración média (entre 1 e 4) de habilidades necesarias para fomentar a empregabilidade

\begin{tabular}{lc}
\hline Habilidade & Valoración Media \\
\hline Experiencia Laboral & 3,60 \\
Actitudes & 3,54 \\
TIC & 3,52 \\
Disponibilidade de movilidade & 3,34 \\
Idiomas & 3,33 \\
Resultados nas probas de selección & 3,09 \\
Especialización & 3,06 \\
Prácticas en empresas & 3 \\
\hline
\end{tabular}

Cando aos participantes, en preguntas abertas se lles preguntaban qué coñecementos adquiridos na formación creen que lle resultarán máis útiles no mundo laboral, respostaron 13 participantes dos 48, e en porcentaxes de prioridade respostaron:

- Coñecementos técnicos específicos_30,77\%

- Casos prácticos de simulación da realidade laboral $23,08 \%$

- Traballo en equipo -15,38\%

- Habilidades de comunicación -15,38\%

- Autocoñecemento - 7,70\%

Por último, cando se lles preguntaba qué actitudes ou valores cree que lle resultarán máis útiles no mundo laboral, tamén en preguntas abertas, respostaron 10 dos 48 participantes, reflexando en porcentaxes de prioridadades as seguintes actitudes e valores:

- Autocontrol e actuación baixo presión - 30\%

- Traballo en equipo - 20\%

- Habilidades de comunicación - 10\%

- Liderazgo - 10\%

- Afabilidade - 10\%
- Curiosidade - 10\%

- Capacidade de aprendizaxe contínua - 10\%

Tras esta primeira medición, os participantes foron asignados ao azar ós grupos control e experimental, pasando cada grupo polos módulos de formación previstos. A seguinte enquisa de medición realizouse 10 meses despóis da primeira.

Neste caso en canto á realidade laboral atopáronse os seguintes datos (Táboa 3):

Táboa 3.

Porcentaxe de situacións laborais en función da pertenza ao grupo experimntal ou control, 10 meses despóis da primeira enquisa.

\begin{tabular}{lcc}
\hline & G.E. & G.C. \\
\hline Traballa por conta allea & $27,3 \%$ & $10 \%$ \\
$\begin{array}{l}\text { Desempregado buscando } \\
\text { traballo }\end{array}$ & $18,2 \%$ & $10 \%$ \\
$\begin{array}{l}\text { Traballa pero quere cambiar } \\
\text { de traballo } \\
\text { Creando propia empresa }\end{array}$ & $0 \%$ & $10 \%$ \\
$\begin{array}{l}\text { Segue a estudiar } \\
\text { Beca de prácticas }\end{array}$ & $9,1 \%$ & $20 \%$ \\
& $18,2 \%$ & $30 \%$ \\
Voluntariado & $\mathbf{1 8 , 2 \%}$ & $10 \%$ \\
$\begin{array}{l}\text { Non traballa nin busca } \\
\text { emprego }\end{array}$ & $0,1 \%$ & $0 \%$ \\
\hline
\end{tabular}

Ante a pregunta “Asistíu a algún seminario de busca activa de emprego nos últimos 10 meses?”, o $81 \%$ do grupo experimental dixo que sí, ademáis da formación recibida, seguiron afondando neste tipo de formación, mentres que o $50 \%$ do grupo control fixo. A valoración deste tipo de formación foi de moi útil para o 77,8\% dos participantes do grupo experimental, mentres que o grupo control a valoraba como Bastante útil nun $80 \%$ dos asistentes a este tipo de formación.

Nesta segunda medición, a importancia das diferentes habilidades profesionais medidas na primeira enquisa xa se pode avaliar de xeito diferencial nos diferentes grupos experimental, e control:

O Grupo Experimental valoraba as seguintes habilidades como máis importantes para acadar e conservar un posto de traballo:

- Proactividade, emprendemento e identificación de oportunidades un $66,7 \%$ dos enquisados 
- Capacidade de adaptación, liderazgo, consecución de recursos e tolerancia ao risco un 55,6\% dos enquisados

O Grupo control valoraba as seguintes habilidades como máis importantes para acadar e conservar un posto de traballo: - Toma de decisión, Adaptación ao cambio e elaboración de proxectos un $80 \%$ dos enquisados. - Solución de problemas, creatividade, capacidade de compromiso, ética profesional, flexibilidade, capacidade de adaptación, proactividade, xestión da información, e identificación de oportunidades, un 60\% dos enquisados

Por último, 24 meses despóis da primeira medición, a situación profesional da mostra, tendo en conta a mortandade experimental tan alta da que xa falamos, é a seguinte (Táboa 4):

Táboa 4.

Porcentaxe de situacións laborais en función da pertenza ao grupo experimntal ou control, 24 meses despóis da primeira enquisa

\begin{tabular}{lcc}
\hline & GE & GC \\
& $\%$ & $\%$ \\
\hline Traballa por conta allea & 22,2 & 44,4 \\
Desempregado en busca de & 55,6 & 22,2 \\
traballo & & \\
Traballa pero quere & 0 & 11,1 \\
cambiar de traballo & & \\
Segue a estudiar & 11,1 & 11,1 \\
Beca en prácticas & 11,1 & 0 \\
Non traballa nin busca & & 11,1 \\
emprego & 0 & \\
\hline
\end{tabular}

Nesta última medición nos interesaba averiguar si ademáis das situacións profesionais referidas, os enquisados tiñan participado noutros proxectos profesionalizantes relacionados coa formación, e neste sentido os resultados amosaron que, nos últimos 12 meses ata a medición:

_ No grupo experimental 3 enquisados participaron en exposicións, traballos de xestión cultural e nun proxecto edtorial, nos que manifestan ter desenvolvido habilidades de autocontrol, liderazgo, traballo en equipo, e creatividade (por este orde de importancia) - No grupo control, 4 persoas participaron en seminarios, exposicións, proxecto editorial e traballo de deseño, desenvolvendo as seguintes habilidades por orden de importancia: Liderazgo e creatividade ao mesmo nivel, autocontrol e traballo en equipo.

En canto á mobilidade laboral obtivéronse os seguintes datos (Táboa 5):
Táboa 5.

Número de empregos, grao de relación coa formación e método para conseguir os empregos, nos grupos control e experimental.

\begin{tabular}{llll}
\multicolumn{3}{c}{ G.E } & \multicolumn{2}{c}{ G.C } \\
\hline $\mathrm{N}^{\mathrm{o}}$ & $\mathrm{N}^{\mathrm{o}}$ & $\mathrm{N}^{\mathrm{o}}$ & $\mathrm{N}^{\mathrm{o}}$
\end{tabular}

Número de persoas empregos persoas empregos

$\begin{array}{lrrrr}\text { empregos } & 1 & 0 & 4 & 0 \\ \text { nos } & 4 & 1 & 5 & 1\end{array}$

derradeiros 3

12 meses $\quad 1 \quad 3$

Media no

Grao de

relación

coa

formación

Escala tipo

Lickert (1

a 4)

\begin{tabular}{|c|c|c|c|c|}
\hline & $\mathrm{N}^{\mathrm{o}}$ & Medio & $\mathrm{N}^{\mathrm{o}}$ & Medio \\
\hline Medio para & Persoas & & Persoas & \\
\hline conseguir & 2 & Contactos & 1 & Contactos \\
\hline \multirow{4}{*}{$\begin{array}{l}\text { os } \\
\text { empregos }\end{array}$} & 1 & Servicios & 1 & Oferta centro \\
\hline & & públicos & & estudios \\
\hline & 6 & Ns/Nc & 3 & $\begin{array}{c}\text { Medios de } \\
\text { comunicación }\end{array}$ \\
\hline & & & 4 & $\mathrm{Ns} / \mathrm{Nc}$ \\
\hline
\end{tabular}

En canto ás habilidades profesionais avaliadas na última enquisa, a valoración da mostra responde ós seguintes resultados (Táboa 6):

Táboa 6.

Porcentaxe de respostas afirmativas en habilidades necesarias para a empregabilidade e que botan en falta nas formacións recibidas, no grupo experimental $e$ control:

\begin{tabular}{lcc}
\hline & G.E & G.C \\
\hline Habilidade & $\%$ & $\%$ \\
Traballo en equipo & 11,1 & 33,3 \\
Liderazgo & 100 & 11,1 \\
Autocontrol & 33,3 & 55,6 \\
$\begin{array}{l}\text { Creatividade } \\
\begin{array}{l}\text { Habilidades de } \\
\text { comunicación }\end{array}\end{array}$ & 100 & 11,1 \\
$\begin{array}{l}\text { Búsqueda de } \\
\text { recursos e } \\
\text { información }\end{array}$ & 22,2 & 100 \\
$\begin{array}{l}\text { Capacidade para } \\
\text { identificar } \\
\text { oportunidades }\end{array}$ & 22,2 & 100 \\
$\begin{array}{l}\text { Elaboración de } \\
\text { proxectos } \\
\begin{array}{l}\text { Coñecementos } \\
\text { técnicos }\end{array}\end{array}$ & 11,1 & 33,3 \\
\hline & 22,2 & 100 \\
\hline
\end{tabular}




\section{Conclusións}

É destacable salientar que a mortandade experimental da mostra seleccionada para ambos grupos dificulta realizar unha análise de resultados que resulte xeneralizable. Ainda así nos plantexamos que os resultados poden ser útiles para orientar futuras investigacións que poidan suplir os posibles fallos que determinasen esta merma tan acusada de suxeitos experimentais: En primeiro lugar, consideramos que sería necesario contar cunha mostra inicial moito máis cuantiosa que permitise compensar a mortandade experimental posterior. Por outra banda, o seguemento da mostra debería ser moito máis asiduo, o que permitise establecer un compromiso de participación máis eficaz.

A pesar da mostra mermada e insuficiente para acadar resultados concluintes, poderíamos facer unha serie de reflexións sobre a tendencia dos resultados:

1.- O grupo experimental, durante o seguemento a tres anos, parece ter unha maior mobilidade laboral (máis número de empregos diferentes no mesmo tempo), pero ademáis expresa vontade e considera útil a formación contínua en búsqueda activa de emprego.

Estos datos parecen coherentes coa realidade laboral actual, nun momento no que a taxa de desemprego se agudiza pola crise económica internacional, a formación contínua é máis que unha necesidade, unha condición imprescindible para adaptarse á competitividade laboral. En canto á mobilidade laboral, podemos dicir que a busca dun emprego que se axuste ás expectativas dos demandantes, neste grupo experimental, podería estar detrás deste proceso de busca contínua da situación laboral máis satisfactoria.

2.- Ningún dos participantes, nin do grupo control nin do grupo experimental, traballa por conta propia na avaliación final (se ben na segunda enquisa o 20\% estaba a desenvolver o seu proxecto no grupo control, e o $9 \%$ no grupo experimental). É curioso que, a pesar da formación en busca activa de emprego no grupo experimental, a posibilidade do autoemprego non fose en ningún caso unha opción profesional válida. Non debemos olvidar a limitada mostra coa que finalmente contamos, pero aínda así, é destacable que a opción de busca de emprego por conta allea sexa a opcoión prioritaria adoptada pola mostra deste estudio.

3.- A consideración de necesidades formativas é diferente por grupos:

- O 100\% dos participantes no grupo experimental salientan a necesidade de formación en: Liderazgo, Creatividade e Coñecementos técnicos específicos.

_ O 100\% dos participantes no grupo control salientan a necesidade de formación en:
Habilidades de comunicación (habilidades sociais), busca activa de recursos e información, e elaboración de proxectos. Podemos intuir que no caso do grupo control non ter recibido nin buscado este tipo de formación estea detrás deste resultado, pero é interesante observar que ata 24 meses despóis da primeira medición, non considerasen que estas habilidades puidesen favorecer a súa formación completa.

Para terminar, é importante salientar que os datos obtidos neste estudio en ningún caso poden considerarse como representativos da poboación seleccionada, entre outros motivos, debido ó escaso éxito da estabilidade da cohorte participante, pero tamén polo escaso control de variables externas ó estudio que puidesen estar detrás dos achádegos, factores que debemos ter en conta para o deseño de futuros estudios que se plantexen neste equipo de traballo. Aínda así, non queremos deixar pasar a oportunidade para destacar a importancia que ten o seguemento a medio e longo prazo, dos egresados que deben contar, e de feito demandan, formación en habilidades e competencias profesionais, que os posicionen nunha situación de ventaxa na incorporación laboral e manteñan a satisfacción profesional e persoal en maior medida.

\section{Referencias}

Alarcón, J.M. (2005). Educar valores en grupo. Málaga: Ediciones Aljibe.

Bennet, C., Foreman-Peck, L., y Higgins, C. (1996) Researching into teaching methods in colleges and universities. London:Cogan Page.

Biggs, J. (2003). Teaching for quality learning at university. Buckingham: The Society for Research into Higher Education and Open University.

Caballo, M. (2005). Manual de entrenamiento y evaluación en habilidades sociales. Madrid: Siglo XXI.

Espada, J. P. (2007). Técnicas de grupo. Recursos prácticos para la educación. Madrid: Editorial CCS.

Gómez-Juncal, M.R., Dopico, D., y Varela, C. (2011) Necesidades formativas percibidas en egresados universitarios de diseño. I+D Diseño. N No10 edición dixital.

(http://www.i-diseno.org/web_ddiseno/ddiseno-10/dol ores_dopico.htm)

Gómez-Juncal, M.R., y Dopico, D. (2008) Comunicación Oral en el $1^{\circ}$ Congreso Internacional de Moda, CIM 2008, celebrado en Madrid del 22 al 24 de octubre de 2008, con el título "El papel de la personalidad y la creatividad en el Diseño de Moda”.

Gómez-Juncal, M.R., y Dopico, D. (2010) Comunicación Oral en el $1^{\circ}$ International congress of design and innovation of Cataluña, celebrado en Sabadell del 18 al 19 de marzo de 2010 con el título "Estilos de enseñanza-aprendizaje: importancia de las 
Comunicación Oral en el $1^{\circ}$ International congress of design and innovation of Cataluña, celebrado en Sabadell del 18 al 19 de marzo de 2010 con el título "Estilos de enseñanza-aprendizaje: importancia de las técnicas de desarrollo de la creatividad en estudiantes de diseño" Publicada en las Actas de Abstracts del congreso (pp.51). ISBN- 978-84-936165-1-9

Hernández, J.S. (2005) Un modelo para formar estilos de aprendizaje crítico y creativo en educación superior. Revista Comportamiento (7), PP. 24-34.

McCormick, Ch. (2002) Metacognition and Learning, en Reynolds, W.M. y Miller, G.E. (eds.), Handbooks of Educational Psychology, Chichester (West Sussex), John Wiley and Sons, pp. 47-57.
Salanova, M., Grau, R. M, y Martínez, I. M. (2005). Demandas laborales y conductas de afrontamiento: el rol modulador de la autoeficacia profesional. Psicothema. Vol 17, no 3. Pp: 390-395.

Sayer, K., y Studd, R. (2006) Matching learning style preferences with suitable delivery methods on textile design programmes. International Journal of Technology and Design Education, 16, 163-176.

VV.AA. (2010). Europa 2020. Una estrategia para un crecimiento inteligente, sostenible e integrador. Comisión europea: Bruselas. 